Original Research Paper

\title{
Modeling the Impact of Taxes on Economic Growth with Regional Resource Potential
}

\author{
Oleg Tsepelev and Maria Kakaulina \\ Department of Finance, Amur State University, Blagoveshchensk, Russia
}

\section{Article history}

Received: 26-09-2014

Revised: 30-02-2015

Accepted: 20-04-2015

Corresponding Author:

Maria Kakaulina

Department of Finance, Amur

State University,

Blagoveshchensk, Russia

Email: beuty1@mail.ru

\begin{abstract}
This study deals with estimation problems for optimal tax burdens in relation to regional economic growth. Theoretical, methodological and empirical base of the research were the concept of the Laffer curve, the materials of the National Research University, Higher School of Economics of the Russian Federation, Ministry of Natural Resources and Environment of the Russian Federation, Federal Service of State Statistics of the Russian Federation, Bureau of Economic Analysis of the United States, National Science Foundation of the United States and California Department of Finance. We propose a classification of subjects of the Russian Federation in accordance with their resource potential. This classification involves a division of regions on commodity and innovation regions. Using this classification and a linear non-homogeneous production function, we develop a model of the impact of the tax burden on regional economic growth. We test the model on the Russian Federation's regional economies. In addition, we use it to calculate optimal values of the tax burden, define the main principles of the impact of taxes on economic growth in the state of California and make proposals for regulating tax legislation. The application our toolkit will help to draw the attention of state authorities at the regional level and will provide an opportunity to form the value of the tax burden involving integration and harmonization of fiscal interests of the state and businesses.
\end{abstract}

Keywords: Tax Burden, Economic Growth, Resource Potential, Laffer Curve, Econometric Models, JEL Classification, H21, C51, C541

\section{Introduction}

Russian President Vladimir Putin stated in his budget message to the Federal Assembly for 2013-2015: "The tax system should not only perform a fiscal function but stimulate business initiative" (Putin, 2012). However, in increasing the tax burden, state authorities often not only fail to solve problems but also create additional problems and unintended economic consequences: Specifically, tax revenues decrease and business entities either are liquidated or start to evade taxes.

Due to changes in the tax legislation of the Russian Federation, which are associated with a doubling of insurance premiums for the self-employed, more than 400,000 sole proprietors were removed from the tax registration in 2012 alone. At the same time, according to experts of the Russian public organization Business Russia, the ensuing loss to the tax base is about 25 billion rubles (Yakovenko, 2013). The emerging institutional trap that has emerged from the tax policy is contrary to legislators' expectations of the policy.

Certain territories are the most vulnerable economies to this situation and the extent of their vulnerability is related directly to regional and local budgets. However, most of the existing procedures for estimating the impact of the tax burden on economic growth have serious limitations in their regional application, including failure to take into account the specific characteristics of territories.

Of particular relevance in this case are questions related to the development of a methodological toolkit that helps in estimating the impact of the tax burden on regional economic growth.

Hence, the objective of this study is to develop a mathematical model for estimating the optimal level of the tax burden in regions, taking into account the interests of the state and businesses.

To achieve this objective, we: 
- Define resource potential

- Classify the subjects of the Russian Federation on the basis of procurement of different kinds of resources

- Develop and test a model of the impact of the tax burden on economic growth, taking into account features of the resource potential of regions

- Make proposals for state authorities to amend tax legislation

\section{Materials and Methods}

Theoretical, methodological and empirical base of the research were the concept of the Laffer curve, the materials of the National Research University, Higher School of Economics of the Russian Federation, Ministry of Natural Resources and Environment of the Russian Federation, Federal Service of State Statistics of the Russian Federation, Bureau of Economic Analysis of the United States, National Science Foundation of the United States and California Department of Finance.

When doing research we used such methods of scientific cognition as regression and variance analyses and econometric methods of research the impact of taxes on the economy.

\section{Basic Terms and Definitions}

There is no universal procedure for estimation of the impact of the tax burden on economic growth at the regional level in Russia because all of its regions are differentiated sharply in terms of economic development. Therefore, it is advisable to apply a model that is typical for certain groups of regions and takes into account the features of their development.

The main criterion for the classification of regions that must be considered first is the resource potential of territories.

In this study, we use the following definition of the resource potential of regions: "The totality of all available resources within its boundaries, as involved in the process of social production and those that could potentially be used for the growth of the economy" (Sapegina and Bochkov, 2013).

Elements of the resource potential of regions are reflected in Fig. 1.

It should be noted that basic labor and capital resources are present in every region, but natural and innovative resources are very unevenly distributed across the country. About $80 \%$ of mineral, land, forest and water resources are in the country's Asian part, while $80 \%$ of innovation potential and skilled workforces are in its European part.

The problem of an uneven distribution of natural resources and innovation in the country causes a delineation of business activity by the two areas, which function in fundamentally different conditions (Pogrebnyak et al., 2009).
The first area is typical of regions with rich natural resource potential; they are characterized by external demand primarily and depend on global market laws and the conjuncture of the world markets for goods, as well as changes in the cost of extraction and production of these resource goods (inflation of offer). These industries are typically oil, gas, timber, woodworking, pulp and paper, chemical and ferrous and non-ferrous metallurgy. However, considering these industries as engines of economic development in the long term is impractical because the growth rates of this sector of economy usually do not exceed $2-3 \%$ per year because natural resources are exhaustible.

The second area is inherent to regions with high innovation potential and depends on the dynamics of domestic demand. This area included innovative complex industries, such as machine building, textile industry, food industry, agriculture and transport. Prospects for the development of these sectors depend on income growth enterprises and households. This requires an active role for the state to mobilize existing reserves of production growth (upgrading of physically and legally obsolete equipment and maximizing the use of spare capacity) and to restore the livelihoods of the majority of the population and, consequently, increase consumer demand.

The natural resource potential of regions is defined by Klochkov (1996) as "all kinds of natural resources (mineral, land, forest, water), which is located in the territory of, is used in the national economy or may be involved into economic circulation at the present level of development of productive forces."

In our opinion, the specific indicators that best reflect the availability of the territory of some natural resources are the initial total resources of the main minerals, the area of agricultural land, the total timber and the annual river flow.

According to Russian consulting group Energy, Regulation, Transport, Analytics (ERTA) (2001), the concept of initial total mineral resources includes cumulative production at the time of estimation, proven reserves and inferred reserves, as well as prospective and probable resources defined on the basis of geological evaluation.

Folomeykina and Igonchenkova (2009) state that innovation potential of territories or regions is "a collection of different kinds of resources, including physical, financial, intellectual, scientific and technical and other resources required for the implementation of innovation activities." One of the most important indicators of the innovative potential of the area is the expenditure on technological innovation, which is "expressed in monetary terms as the actual costs associated with implementation of the various types of innovation activities carried out at regional level” (Hochberg, 2011). 


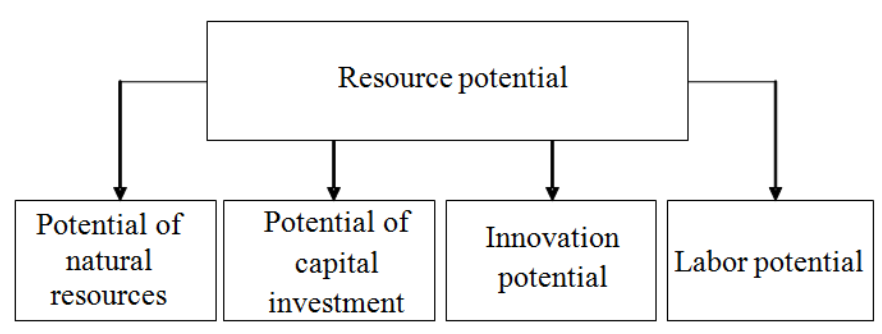

Fig. 1. Elements of the resource potential of regions Source: Compiled by authors

\section{Results}

\section{Classification of Subjects of the Russian Federation} in Terms of Resource Potential

In considering existing areas of economic activity, we develop a classification of subjects of the Russian Federation in accordance with their resource potential. This classification involves a division of regions on commodity and innovation regions.

Group A denotes commodity regions, which have an inflow of investments and financial assets mainly due to wealth of natural resources.

This group of regions comprises four subgroups, delineated by natural resources that are predominant in each region. These sub-groups are:

$A_{m}$ : A subgroup of regions with a large supply of mineral resources, such as Tyumen region, including Khanty-Mansi Autonomous Area-Yugra (KhMAA) and Yamal-Nenets Autonomous Area (Yamal) and Arkhangelsk region, including Nenets Autonomous Area.

$\mathrm{A}_{\mathrm{g}}$ : A subgroup of regions with a large supply of land resources, for example, the Altay, Orenburg, Volgograd and Rostov regions.

$\mathrm{A}_{\mathrm{f}}$ : A subgroup of regions with a large supply of forest resources, which includes the Republic of Buryatia, Primorsky Krai, Vologda and Kirov regions.

$\mathrm{A}_{\mathrm{w}}$ : A subgroup of regions with a large supply of water resources, including regions such as Astrakhan region, Jewish Autonomous Region, Amur region and Komi Republic.

In addition, there is a group of innovative regions characterized by highly developed production, knowledge-intensive industries and advanced infrastructure, which is denoted as group B in this study. The innovative regions of Russia are Moscow, Moscow region, St. Petersburg, Tomsk region, Nizhny Novgorod region, Novosibirsk region and the Republic of Tatarstan.

Classification of subjects of the Russian Federation by resource potential is imaged in Fig. 2.

\section{Valuation of the Mineral Resource Base of Russian Regions}

Evaluating regions by mineral resources in physical terms is difficult because of incommensurability of measurements. For example, some types of minerals are expressed in mass units (e.g., cement, coal, copper, iron ore, lead, oil and zinc) and some in volume units (e.g., building sand, clay and loam, natural gas and peat).

Hence, there is a need for valuing the mineral resource base regions of Russia. Since the structure, value of the potential and significance of certain types of resources are not the same, their evaluation is always relative.

There are different methods of valuing mineral resources. The cost (value) of subsoil is understood as "the gross value of minerals in the ground" (Nezhensky and Pavlova, 1995). This is determined by the product of the average world price of the final product by the number of stocks. In our study, we use average national prices for Russian regions instead of average world prices.

Thus, the gross value of the mineral resource base of each region is determined by the following Equation 1:

$M_{\text {cost }}=\sum_{i=1}^{14} P_{i} M_{\text {inat }}$

Where:

$P_{i} \quad=$ The Russian average price of the $i$-th industrial good

$\mathrm{M}_{\text {inam }}=$ The initial total of the $i$-th mineral resource in the region

Russia's regional leaders in terms of gross value of the mineral resource base are the Tyumen region (including KhMAA and Yamal), KhMAA and the Kemerovo region.

Dynamics of the gross value of the mineral resource base these regions is represented in Fig. 3.

Indicator of the gross value of mineral resources may be used to compare regions of the Russian Federation for their provision of these kinds of resources and to analyze the dynamics of the general state of the regional mineral resource base. In contrast to an index of initial total mineral resources in physical terms, this indicator is comparable to those of other regions and is more informative because it considers annual price fluctuations.

\section{Empirical Model and Estimation Procedure}

There are many existing models of the impact of the tax burden on economic growth based on the concept of 
the Laffer curve and the most widely used among them is the static three-factor model proposed by Balatsky (2003). This model based on Cobb-Douglas production function (Cobb-Douglas production function is a particular functional form of the production function, widely used to represent the technological relationship between the amounts of two or more inputs, particularly physical capital and labor and the amount of output that can be produced by those inputs).

We adopt the view of Ananiashvili and Papava (2010) that the "Cobb-Douglas production function, even in the aggregate, in which it is represented in the model of the impact of the tax burden on economic growth E.V. Balatsky not be considered as a universal model, reflecting the impact of institutional factors, the tax on the economy, in particular."

Therefore, in systematizing the most widespread of the production functions in the economic literature and determining the range of application for each of them, we propose to use a non-homogeneous linear three-factor production function as the basis of our model to explain the interaction of the tax burden and economic growth.

In economic theory, the factors of production include labor, capital, land (natural resources), entrepreneurial ability and scientific and technical progress. In the simulation function for the regions of group A, the factor of natural resources is as necessary as the factors of labor and capital. For the regions of group $\mathrm{B}$, in addition to labor and capital, the most important factor is scientific and technological progress (innovation). The impact of the other factors is expressed through the productivity of the three abovementioned resources and remains quite stable for long periods of time.

Thus, our proposed model of the impact of the tax burden on economic growth is as follows:

For regions in subgroup $\mathrm{A}_{\mathrm{m}}$ :

$$
\begin{aligned}
& Y=(a+b T) T L+(c+d T) T K+(m+n T) T M+B \\
& Q=(a+b T) T^{2} L+(c+d T) T^{2} K+(m+n T) T^{2} \times M+B T
\end{aligned}
$$

Where:

Y

K

$L$

$T$

Output (volume of Gross Regional Product (GRP)) (million rubles)

$=$ Tax revenues (amount of taxes, fees and other mandatory payments to the consolidated budget of the Russian Federation from the territory of a particular region (million rubles)

$=$ Capital (volume of fixed assets of the region) (million rubles)

$=$ Labor (number of employed workers in the regional economy) (thousand people)

$=$ The gross value of the mineral resource base (billion rubles)

$=$ the relative tax burden (calculated as a share of tax revenues in the GRP $T=Q / Y)(\%)$

$a, b, c, d, m, n$ and $B=$ The parameters evaluated statistically based retrospective time series

For regions in subgroup $A_{g}$ :

$Y=(a+b T) T L+(c+d T) T K+(m+n T) T G+B$

$Q=(a+b T) T^{2} L+(c+d T) T^{2} K+(m+n T) \times T^{2} G+B T$

Where:

$G=$ The area of agricultural land (thousand acres)

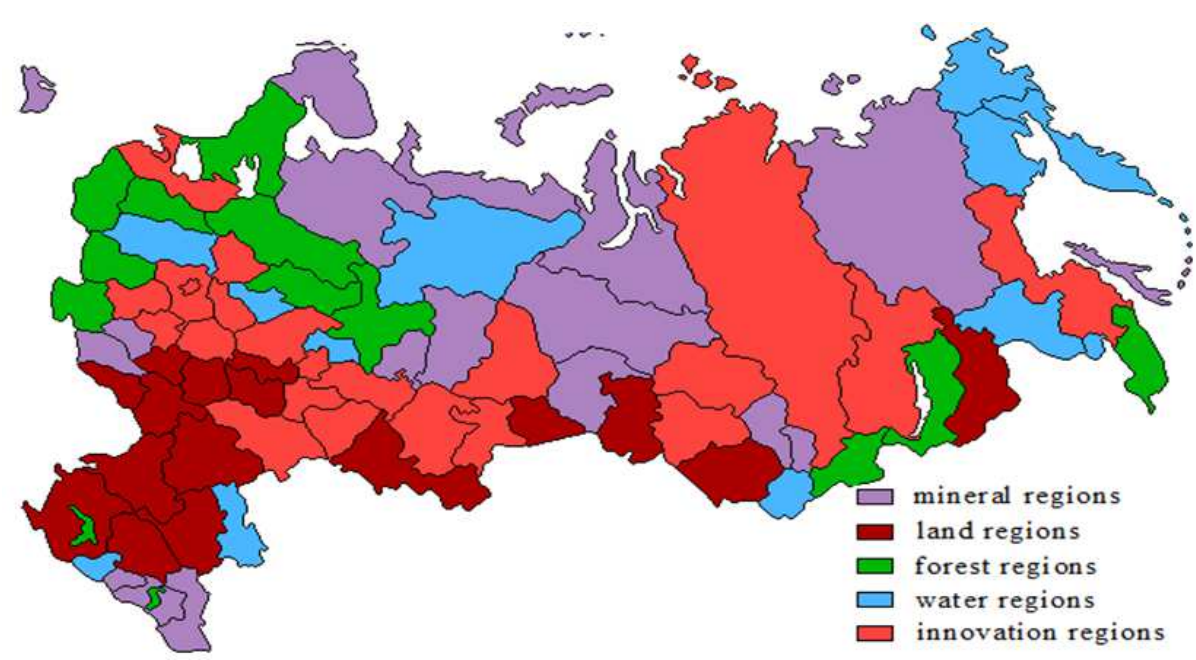

Fig. 2. Classification of subjects of the Russian Federation by resource potential Source: Compiled by authors 


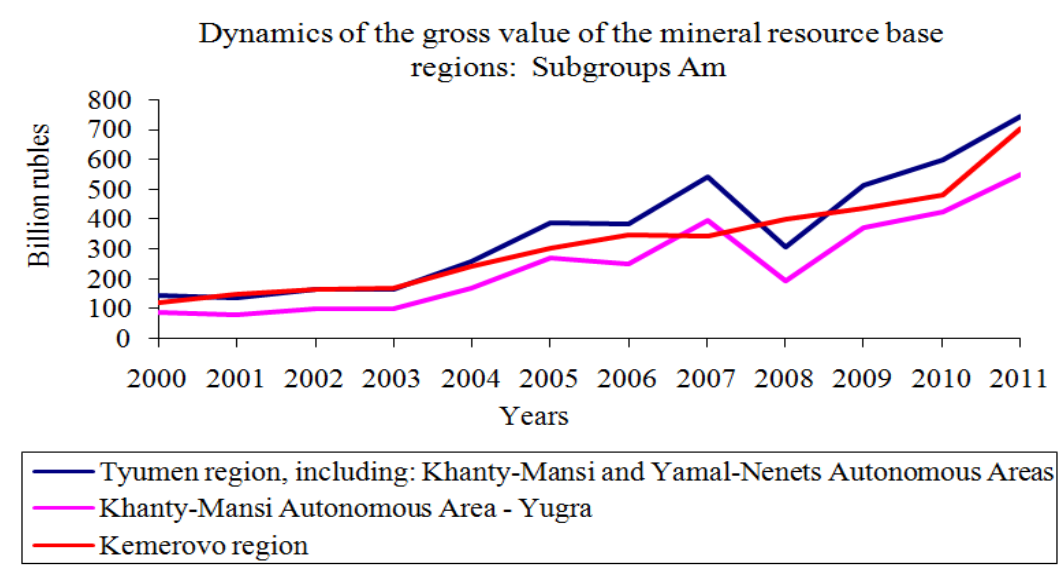

Fig. 3. Dynamics of the gross value of the mineral resource base regions: Subgroups Am for 2000-2011 Source: Compiled by the authors using official statistical data of the Federal Service of State Statistics of the Russian Federation and Ministry of Natural Resources and Environment of the Russian Federation

For regions in subgroup $A_{f}$ :

$$
\begin{aligned}
& Y=(a+b T) T L+(c+d T) T K+(m+n T) T \times F+B \\
& Q=(a+b T) T^{2} L+(c+d T) T^{2} K+(m+n T) \times T^{2} F+B T
\end{aligned}
$$

Where:

$F=$ Total timber $\left(\right.$ million $\left.\mathrm{m}^{3}\right)$

For regions in subgroup $\mathrm{A}_{\mathrm{w}}$ :

$$
\begin{aligned}
& Y=(a+b T) T L+(c+d T) T K+(m+n T) T \times W+B \\
& Q=(a+b T) T^{2} L+(c+d T) T^{2} K+(m+n T) \times T^{2} W+B T
\end{aligned}
$$

Where:

$W=$ Annual river flow $\left(\mathrm{km}^{3}\right)$

For regions in group B:

$$
\begin{aligned}
& Y=(a+b T) T L+(c+d T) T K+(m+n T) T \times I+B \\
& Q=(a+b T) T^{2} L+(c+d T) T^{2} K+(m+n T) \times T^{2} I+B T
\end{aligned}
$$

Where:

$I=$ The expenditure on technological innovation (million rubles)

Our model specifies that the quadratic functions of the tax burden are the ultimate output factors.

In assessing the impact of the tax burden on economic growth, our main task is to determine the relative position of fiscal indicators-the Laffer points of the first and second kind and the actual tax burden.

The Laffer point of the first kind is called the value of the tax burden at which the production curve $Y(T)$ reaches a local maximum, that is, when $\partial Y / \partial T=0$. In economic terms, the Laffer point of the first kind refers to the limit of the tax burden in which the economy does not enter recession (Gusev, 2003). Therefore, this point is the upper limit of the optimal tax burden in relation to economic growth. The formula for calculating the Laffer point of the first kind of Function (2) has the form:

$$
T^{*}=-\frac{a L+c K+m M}{2(b L+d K+n M)}
$$

The Laffer point of the second kind is called the value of the tax burden at which the fiscal curve $Q(T)$ reaches a local maximum, that is, when $\partial Q / \partial T=0$. The Laffer point of the second kind indicates the amount of the tax burden, beyond which the value of tax revenue begins to decline (Gusev, 2003). This fiscal indicator Function (3) is determined by the following formula:

$$
\begin{aligned}
& T^{* *}= \pm \frac{\sqrt{(a L+c K+m M)^{2}-3(b L+d K+}}{3(b L+d K+n M)} \\
& \underline{\sqrt{n M) \times B}-(a L+c K+m M)}
\end{aligned}
$$

The Laffer point of the second kind is the maximum point from two fixed points, calculated in accordance with Equation 13.

Similarly, we determine the Laffer point for the other models.

The next important aspect of the analysis is that this form of functional dependence implies combining the technological and fiscal factors of economic growth. This is manifested in the fact that the direction of the impact of labor, capital and natural resources (or innovation) to output (derivative sign $\partial Y / \partial L, \partial Y / \partial K$ and 
$\partial Y / \partial M$, respectively) non-linearly depends on the value of the tax burden. Therefore, the analysis of fiscal indicators appears in the form of switching points, corresponding to stationary conditions $\partial Y / \partial L=0, \partial Y / \partial K$ $=0$ and $\partial Y / \partial M=0$ and is calculated as:

$$
T_{L}=-\frac{a}{b}
$$

$T_{K}=-\frac{c}{d}$

$T_{M}=-\frac{m}{n}$

Where:

$T_{L}=\mathrm{A}$ maximum point of the curve of marginal productivity of labor $(\%)$

$T_{K}=\mathrm{A}$ maximum point of the curve of marginal productivity of capital (\%)

$T_{M}=\mathrm{A}$ maximum point of the curve of marginal productivity of natural resources (innovation) (\%)

Thus, if the parabola $E L=a T+b T^{2}$ is convex upwards, when the tax burden below level of Equation 14 , the marginal productivity of labor is positive and any increase in the number of employed workers in the economy leads to an increase in output. Upon reaching the level of the tax burden represented by Equation 14, the marginal productivity of labor becomes negative and extensive increases in the number of employed workers in the economy will cause production recession. On the other hand, if the parabola is convex downwards, the opposite situation occurs. A similar regularity is manifested in the switching points (15)-(16). Thus, the technological and fiscal analyses are combined: Technological characteristics, such as the marginal productivity of labor, capital and natural resources (innovation), depend directly on the value of the tax burden.

The model of this study impels the following formula to calculate the elasticity of substitution of capital for labor $\mathrm{E}_{1}=(L / K)(\partial K / \partial L)(\%)$, the elasticity of substitution of capital for natural resources (or innovation) $\mathrm{E}_{2}=(M / K)(\partial K / \partial M)(\%)$ and the elasticity of substitution of labor for natural resources (or innovation) $\mathrm{E}_{3}=(M / L)(\partial L / \partial M)(\%)$ :

$E_{l}=-\frac{L(a+b T)}{K(c+d T)}$

$E_{2}=-\frac{M(m+n T)}{K(c+d T)}$

$$
E_{3}=-\frac{M(m+n T)}{L(a+b T)}
$$

\section{Advantages and Disadvantages of the Proposed Model}

In theory, our proposed functions (2)-(3) are fitting.

First, at the extreme values of the tax burden $T$, these functions behave satisfactorily; on the left margin, at zero taxation $(T=0)$, output exists and is equal to the value $B$ and tax revenues are missing $(Q=0)$. Thus, the fiscal curve on the left margin is in line with classical theory. The requirement of equality to zero of output at this point is narrow and can be considered valid, that it equals conditionally small amount.

On the right margin, at $100 \%$ taxation $(T=1)$, the value of output and tax revenues logically coincide with $(Y=Q)$ and $Y=(a+b) \mathrm{L}+(c+d) K+(m+n) M+B$. Although this value is not zero, it is arbitrarily close to zero at specific values of the parameters.

The relative position of the production and fiscal curves is reflected in Fig. 4.

Second, the introduced Function (2) has all the properties inherent in a linear non-homogeneous production function.

Production is possible in the absence of one or more factors of production so long as the absolute term $\mathrm{B} \neq 0$ :

$$
\begin{aligned}
& F(0, K, M, T)=\left(c T+d T^{2}\right) K+\left(m T+n T^{2}\right) M+B, \\
& F(L, 0, M, T)=\left(a T+b T^{2}\right) L+\left(m T+n T^{2}\right) M+B, \\
& F(L, K, 0, T)=\left(a T+b T^{2}\right) L+\left(c T+d T^{2}\right) K+B, \\
& F(L, K, M, 0)=B, F(0,0,0,0)=B .
\end{aligned}
$$

The function is continuous.

As resources increase, output increases:

$$
\begin{aligned}
& F_{L}^{\prime}(L, K, M, T)=a T+b T^{2}>0, \\
& F_{K}^{\prime}(L, K, M, T)=c T+d T^{2}>0, \\
& F_{M}^{\prime}(L, K, M, T)=m T+n T^{2}>0, \\
& F_{T}^{\prime}(L, K, M, T)=\left(a+2 b T^{3}\right) L \\
& +\left(c+2 d T^{3}\right) K+\left(m++2 n T^{3}\right) M>0 .
\end{aligned}
$$

These conditions are not always satisfied and their implementation depends on the specific values of products and factors of production.

An unbounded increase in the output of one resource approaches infinity:

$$
\begin{aligned}
& F(\infty, K, M, T)=F(L, \infty, M, T)=F(L, K, \infty, T)= \\
& =F(L, K, M, \infty)=\infty .
\end{aligned}
$$

The function is heterogeneous so long as the absolute term $B \neq 0$; thus, a uniform increase in all factors of production does not cause a proportional increase in product: $F(p L, p K, p M, \mathrm{pT}) \neq p^{h} F(L, K, M, T)$, when $p>0$. 


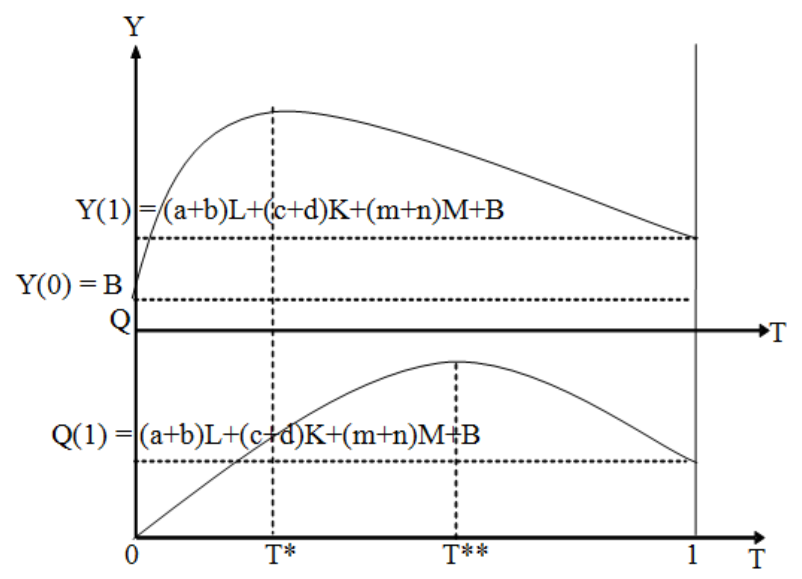

Y-output; Q-tax revenues; T-actual tax burden; T* -Laffer point of the first kind; $\mathrm{T}^{* *}$-Laffer point of the second kind; K-capital; Llabor; M-mineral resources; $\mathrm{a}, \mathrm{b}, \mathrm{c}, \mathrm{d}, \mathrm{m}, \mathrm{n}$ and B-parameters evaluated statistically based on retrospective time series

Fig. 4. The relative position of the production and fiscal curves Source: Compiled by authors

That is, there is no number $h$ such that the equality:

$$
\begin{aligned}
& a p^{2} T L+b p^{3} T^{2} L+c p^{2} T K+d p^{3} T^{2} K+m p^{2} T \times \\
& \times M+n p^{3} T^{2} M+B=p^{h}\left(a T L+b T^{2} L+c T K+\right. \\
& \left.+d T^{2} K+m T M+n T^{2} M+B\right)
\end{aligned}
$$

Our model has a significant mathematical disadvantage.

In Models (2)-(3), the impact of the tax burden on the economic system and its characteristics by using the marginal productivity of labor, the marginal productivity of capital and the marginal productivity of natural resources (innovation), i.e., $E L=(a+b T) T, E K=$ $(c+d T) T$ and $E M=(m+n T) T$.

Marginal activities are calculated by the following formulas:

$E L(T)=\partial Y(T) / \partial L$

$E K(T)=\partial Y(T) / \partial K$

$E M(T)=\partial Y(T) / \partial M$

On the basis of the economic content of the activities of marginal productivity of labor, capital and natural resources (innovation), their values must be non-negative.

According to the our preliminary calculations (Tsepelev and Kakaulina, 2014), for functions $E L(T)$, $E K(T)$ and $E M(T)$ applicable to some regions (e.g., Ivanovo, Kursk, Lipetsk, Orel, Smolensk, Tambov, Tver and Yaroslavl), the condition is not only met but the existence that $T$ would satisfy a system of inequalities is very problematic, which is shown as follows:

$$
\left\{\begin{array}{l}
(a+b T) T \geq 0, \\
(c+d T) T \geq 0, \\
(m+n T) T \geq 0, \\
0 \leq T \leq 1 .
\end{array}\right.
$$

This means there is no allowable value of the tax burden at which activities of the marginal productivity of labor, capital and natural resources (or innovation) are non-negative at the same time in those regions.

\section{Testing the Proposed Model}

In testing the applicability of our model to the subjects of the Russian Federation, we use two principles. First, the series length should not be more than 17 years because the computational accuracy decreases in the study with long time periods; and second, analyzed periods should be close to the present time. Therefore, given the availability of the required official statistical information, we review the period from 2000 to 2011.

Units of labor, capital and natural resources correspond to the units used in official statistics.

It should be noted that the values of the actual tax burden in the Ingushetia, Kalmykia, Mordovia, Altai Republic and Chukotka Autonomous Area are not included in the tolerance range (above 100\%), which indicates that the estimation of the impact of this indicator on economic growth, based on the concept of the Laffer curve for these regions, is inappropriate.

Thus, the obtained values of the Laffer points of the first and second kind for 33 regions of the Russian Federation are not included in the tolerance range. This effect is explained by the fact that there is no allowable value of the 
tax burden at which activities of the marginal productivity of labor, capital and natural resources (or innovation) are non-negative at the same time in those regions.

Nevertheless, it should be noted that our method allows us to solve the problem of estimating the impact of the tax burden on economic growth for St. Petersburg; Belgorod, Irkutsk, Kemerovo, Pskov, Sakhalin, Tomsk regions; Chechnya, Karelia, Komi, North Ossetia (Alania), Tatarstan and Tuva Republics; Perm Krai. If the values of fiscal indicators calculated for these regions on the basis of other models are not included in the tolerance range, the Laffer points obtained on the basis of our model are within acceptable limits.

\section{Empirical Research in California}

The practical significance of this study's proposed model is confirmed by the possibility of its application beyond the Russian economy. It could be a tool for cross-country comparisons of certain areas for the purpose of finding features of the impact of taxes on economic growth. In order to test the functionality of our model, we use the example of the State of California, United States.

California is classified as an innovative state because it includes Silicon Valley, a high-density territory of hightech companies that develop and produce computers and components, in particular, microprocessors, software, mobile devices and biotechnology.

In this regard, Models (10)-(11), developed for the regions of Group B, are suitable to assess the fiscal climate of California.

When estimating indicators of expenditure on technological innovation, we encounter a methodological problem because this activity is not accounted for in California. Thus, we substitute this activity with costs for scientific and experimental Research and Development (R and D).

Parameters of the econometric model for the State of California in 2000-2011 are represented in Table 1.

Our econometric model passes all the basic statistical tests, including the t-statistic of the regression coefficients at a $95 \%$ level of significance.

Dynamics of fiscal indicators in California's economy for 2000-2011 is shown in Fig. 5.

The most interesting results of the fiscal analysis for California are as follows.

First, the values of both the Laffer points and the actual tax burden are significantly lower than in the regions of Russia. They are similar only in respect of the values of fiscal indicators of the Republic of Dagestan and the Republic of Tuva. This is due to small amounts of tax revenues to the consolidated budget of the United States from the territory of California.

Second, the actual tax burden never exceeds the Laffer point of the second kind. This effect indicates that tax does not restrain the growth rate of tax revenues in California during the period of analysis.

Third, California is a unique area from a technological perspective. The values of switching points are $T_{L}=14.42 \%, T_{K}=6.33 \%, T_{I}=7.00 \%$. Moreover, the marginal productivity of labor and the marginal productivity of innovation are parabolas of the convex upward variety, while the marginal productivity of capital is a parabola of the convex downward variety. Consequently, the marginal productivity of labor, capital and innovation are positive simultaneously and the actual tax burden should be in the range: $T_{K}<T<T_{I}(6.33 \%<T<7.00 \%)$.

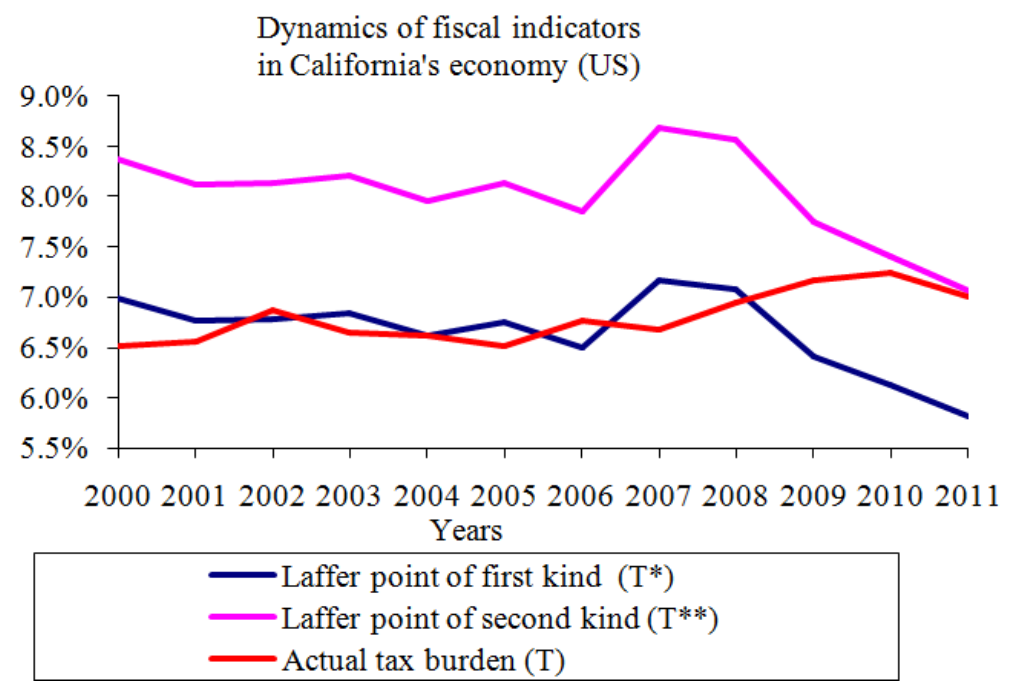

Fig. 5. Dynamics of fiscal indicators in California's economy for 2000-2011 Source: Compiled by the authors using official statistical data of the Bureau of Economic Analysis of the United States, California Department of Finance and National Science Foundation of the United States 


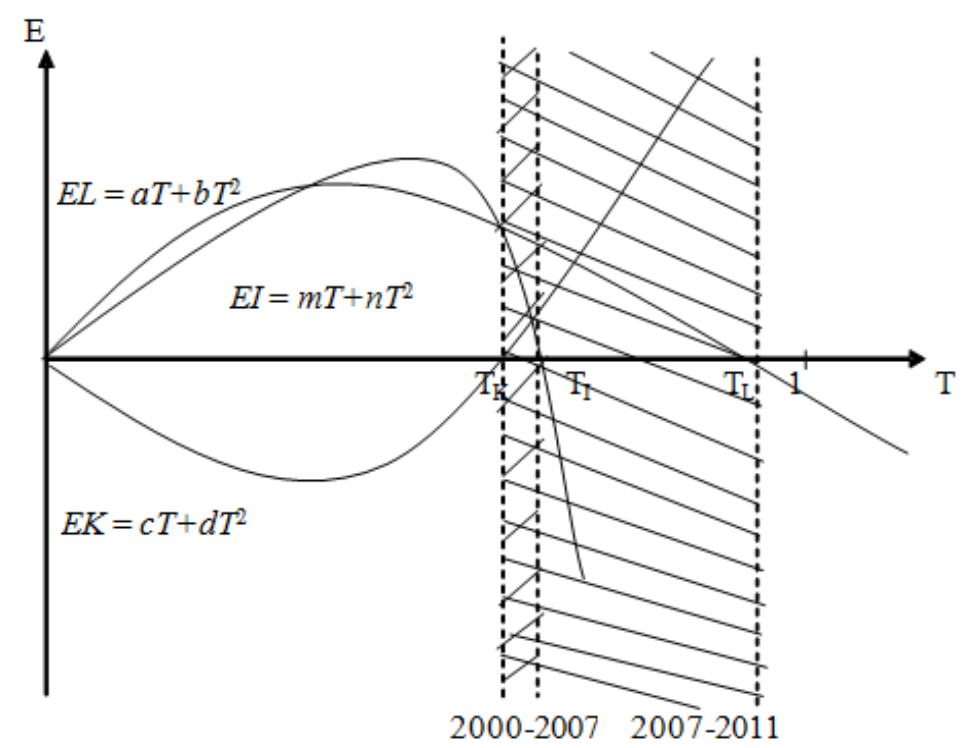

E-elasticity of substitution; EK-marginal productivity of capital; ELmarginal productivity of labor; EI-marginal productivity of innovation; $\mathrm{T}$-actual tax burden; $\mathrm{T}_{\mathrm{K}}$-tax burden, at which the marginal productivity of capital changes sign; $T_{L}$-tax burden, at which the marginal productivity of labor changes sign; $\mathrm{T}_{\mathrm{I}}$-tax burden, at which the marginal productivity of innovation changes sign; $a, b, c, d, m, n-$ parameters evaluated statistically based on retrospective time series

Fig. 6. Band technologically effective values of the tax burden Source: Compiled by authors

Table 1. Parameters of the econometric model for the State of California for 2000-2011

\begin{tabular}{llllllll}
\hline Coefficients activities & $\mathrm{a}$ & $\mathrm{b}$ & $\mathrm{c}$ & $\mathrm{d}$ & $\mathrm{m}$ & $\mathrm{n}$ & $\mathrm{B}$ \\
\hline Value of a quantity & $3,972.82$ & $-27,546.52$ & -6.78 & 107.08 & $394,438.34$ & $-5,629,834.72$ & $-1,416,939.68$ \\
T-statistic & 1.11 & -0.66 & -0.23 & 0.25 & 0.46 & -0.45 & -1.16 \\
Statistical parameters & & $\mathrm{R}^{2}=0.925 ;$ & $\mathrm{F}=10.25 ; \mathrm{DW}=1.35 ; \mathrm{E}=1.50 ;$ & $\mathrm{N}=12$ & \\
\hline
\end{tabular}

$\mathrm{R}^{2}$ : Coefficient of determination, F: Fisher statistics, DW: Durbin-Watson statistic, E: Average error of approximation and N: number of observations

Figure 5 shows that the value of the tax burden belongs to this interval in 2000-2008. During this period, elasticities are negative simultaneously, although without sustainable dynamics. The period 2009-2011 is characterized by a positive marginal productivity of labor and capital and a negative marginal productivity of innovation because the actual tax burden is in the range $(7.00 \%<T<14.42)$ in this period. This causes a negative elasticity of substitution of capital for labor against a background of positive elasticities of substitution of capital and labor for innovation.

The graphical representation of this regularity is shown in Fig. 6.

Thus, the excess of the tax burden from 2009 in the upper optimum value (Laffer point of the first kind) has led to an imbalance of macroeconomic factors. That is, in the period 2009-2011, higher taxes in California hindered scientific and technological progress.

\section{Conclusion}

We make the following proposals based on our research.

First, US government authorities should take measures to reduce the tax burden in the state of California to the level of $5.82 \%$, because this level not only surpasses the Laffer point of the first kind but also almost reaches the Laffer point of the second kind. If the tax burden is not reduced, the state's budget will be harmed in the near future.

Second, it is advisable for state authorities to calculate annually the optimal level of tax burden on subjects and to take this level as a reference point when setting tax rates.

Our proposed model of the impact of the tax burden on economic growth has several advantages, as follows: 
- The present model is fairly simple to build and is based on linear dependence

- The model takes into account the specific economic development of each region and in particular, its resource potential, which allows for the accurate determination of the optimal tax burden

- This model is suitable for estimating the impact of the tax burden on the economic growth of 45 regions of the Russian Federation, while the dynamic and static three-factor models are suitable for only 39 regions

- From our viewpoint, our model has only one mathematical disadvantage, while most models of the impact of the tax burden on economic growth usually have many disadvantages

Thus, the results of our calculations from a model of the impact of the tax burden on economic growth, based on a linear production function and taking into account regional resource potential, reliably reflect the regional fiscal climate.

Our proposed classification can be used for crossregional comparisons, the creation of regional ratings of resource potential and the development of methods and analyses of socioeconomic development of certain regions and the entire Russian Federation. Our model can be applied by state authorities to subjects of the Russian Federation for evaluating basic parameters of the regional tax system involving integration and harmonization of fiscal interests of the state and businesses.

\section{Acknowledgement}

This research was supported by the research project of the Amur State University № 114102270123 «Regional Aspects of Financial-Economic Systems Management ».

\section{Funding Information}

Source of external funding used in the research supporting the paper is cash grant of Amur State University.

\section{Author's Contributions}

Maria Kakaulina: Collection of statistical information and application calculations.

Oleg Tsepelev: Making proposals, conclusions and directions for future research.

\section{Ethics}

This article is original and contains unpublished material. The corresponding author confirms that all of other authors have read and approved the manuscript and no ethical issues involved.

\section{References}

Ananiashvili, Y. and V. Papava, 2010. Taxes and Macroeconomic Equilibrium: The Laffer-Keynesian Synthesis. 1st Edn., Publishing House CA and CC Press, Stockholm, pp: 142.

Balatsky, E. 2003. Analysis of the impact of the tax burden on economic growth through production and institutional functions. Проблемы прогнозирования (Problems of Forecasting), 2: 88-107.

USDC, 2104. Bureau of Economic Analysis. USDC, United States. www.bea.gov

SC, 2014. California Department of Finance. State of California, United States. www.dof.ca.gov

FSSS, 2004. Federal Service of State Statistics of the Russian Federation. www.gks.ru.

Folomeykina, L. and O. Igonchenkova, 2009. The innovative potential of the region: Approaches to the study. Actual Problems Geography Geoecol.

Gusev, A., 2003. Taxes and Economic Growth: Theory and Empirical Estimates. 1st Edn., Economics and Law, Moscow, pp: 139.

Hochberg, L., 2011. Russian Innovation Index, National Research University/Higher School of Economics. 1st Edn., Moscow, pp: 84.

Klochkov, V., 1996. The determination of naturalresource potential of the territory as a part of optimization of nature management. Territorial organization of society and governance in the regions. Voronezh.

MNRERF, 2009. On the status and use of the mineral resource base regions of the Russian Federation. Ministry of Natural Resources and Environment of the Russian Federation.

NSF, 2014. National Science Foundation, United States.

Nezhensky, N. and I. Pavlova, 1995. Methodical bases of valuation Russian subsoil. Mineral Resources Russia, Economics Manage., 4: 13-17.

Pogrebnyak, R., M. Zhukova and C. Tuskaeva, 2009. The influence of the tax burden to the economic growth of the regions with different natural resource potential. Audit Financial Analysis, 1: 12-16.

Putin, V., 2012. On budget policy: Budget message of the president to federal assembly from 28 June 2012.

Sapegina, O. and M. Bochkov, 2013. The socioeconomic potential of the region: The nature and structure. Economy and management: Theoretical and practical aspects. Proceedings of the International Correspondence Theoretical and Practical Conference, (TPC' 13), Siberian Association of Consultants, Novosibirsk, pp: 76-80.

Tsepelev, O. and M. Kakaulina, 2014. Modeling the impact of tax burden on economic growth with regional resource potential. 1st Edn., Far East Science, Vladivostok, pp: 428.

Yakovenko, D., 2013. Taxes "scorched earth". Expert, 17-18: 58-60. 